\title{
Narrativas artísticas: ramificações, contaminações e apagamentos
}

Artistic narratives: ramification, contamination, and erasure

\author{
FÁBIOFONSECA \\ Universidade Federal de Uberlândia (UFU), Brasil
}

NIKOLETA KERINSKA

Universidade Federal de Uberlândia (UFU), Brasil

PRISCILA RAMPIN

Universidade de Brasília (UnB), Brasil

\section{RESUMO}

Esta edição dedica-se às ações e projetos artísticos contemporâneos de caráter narrativo. Ao reunir contribuições de várias nacionalidades, revela-se a heterogeneidade dos modos de narrar e a identificação dos métodos e procedimentos de elaboração e apresentação dessas obras, que se estruturam com base em elementos visuais, áudio e verbo visuais, tanto de natureza ficcional quanto documental, e/ou híbrida.

\section{PALAVRA S-CHAVE}

Narrativas artísticas, texto e imagem, ficção, duco-ficção, arte contemporânea.

\begin{abstract}
A B S T R AC T
This edition is dedicated to the contemporary artistic actions and projects with a narrative character. By bringing together contributions from various nationalities, the heterogeneity of the modes of narration and the identification of methods and procedures are revealed. The art works or theoretical analysis are structured on the basis of audio and visual elements or text and visual, both of a fictional and documentary nature, and/or hybrid.
\end{abstract}

\section{KEYWORDS}

Artistic narratives, text and image, fiction, duco-fiction, contemporary art. 
Era uma vez... essa combinação de palavras de poder mágico é talvez uma das expressões mais conhecidas e comumente aceitas; seu enunciado retém a atenção e mobiliza intuitivamente a consciência do ouvinte. Segundo o Oxford English Dictionary, a expressão once upon a time tem sido usada na língua inglesa desde o século XIV, enquanto o uso de il était une fois é atribuído à Charles Perrault em sua obra "Os desejos ridículos", datada por volta de 1694. Esta deve ser uma das expressões mais fáceis para os tradutores, pois ela conta com transposições de sentido semelhante em mais de 60 línguas, e, talvez, não haja sequer um idioma que não a contemple. Uma coisa é certa: essa fórmula de origem popular, utilizada para introduzir narrativas orais para crianças, é prescindível de qualquer explicação, seu significado e seu uso são claros. E, se nos perguntarmos quando a ouvimos pela primeira vez, ou, em quais circunstâncias, é quase impossível de identificar o momento deste precioso encontro.

Assim, pode-se pensar que essa universalidade decorre de uma habilidade humana de contar histórias, que pode ser vista como antropologicamente determinante para a espécie. Essas ideias coincidem com a hipótese de Bernard Victorri ${ }^{1}$, segundo a qual, a função narrativa da linguagem estaria na própria raiz do surgimento da linguagem humana (VICTORRI, 2002, p. 116). Assim, o que distinguiria o Homo sapiens de outras espécies seria a capacidade de contar sua própria história, sendo esta a fonte de novas sabedorias, constituindo o fundamento das sociedades humanas. Contar ou em outros termos, narrar, seria assim uma atividade que marca as práticas sociais.

Para melhor entender o ato de contar e a capacidade narrativa, recorremos às reflexões de Sylvie André (2012, p. 34) que entende a narrativa como "forma universal da representação da experiência temporal por meio da linguagem humana”. Nesse sentido, a narrativa se apresenta como a estrutura essencial do conhecimento e da organização dos significados, ou ainda, como uma atividade diretamente relacionada com a capacidade humana de simbolizar ou de mimetizar. Uma pergunta legítima seria: é possível fazer uma distinção concreta entre o ato de narrar e o de conceber ideias?

A formulação e a transmissão de ideias, que envolvem o uso de linguagens, são marcos característicos do desenvolvimento cultural das diversas sociedades. A linguagem, como meio de construir e transmitir conhecimento, transita entre o corpo, a escrita e a imagem, que se complementam, atuando de diferentes maneiras e em diferentes campos perceptivos. Uma história pode ser preservada na memória e contada oralmente, ou em algum suporte representada por meio de figuras e sinais gráficos. Contar uma história com palavras ou imagens é uma prática humana que permeia toda atividade simbólica, contribuindo com a construção da noção das artes cênicas, literárias e visuais.

Ao longo dos últimos dois séculos, com a popularização da literatura como prática artística e social no Ocidente, a narrativa se impôs como estrutura essencial de conhecimento, e, sua dimensão antropológica e cognitiva se tornaram objeto de inúmeras investigações. Enquanto isso, seu modo e suportes semióticos constituem um campo de criação e de pesquisa, fortemente

1 Essa hipótese é desenvolvida inicialmente por Mark Turner no livro “The Literary Mind”, Oxford University Press, 1996 (ver capítulo 8) e posteriormente retomada por Victorri. 
diversificado pelas tecnologias atuais. Neste contexto, as relações entre texto e imagem, como códigos complementares na construção de uma mensagem, são frequentemente abordadas em termos analíticos e comparativos.

Sob uma perspectiva histórica, a imagem é examinada como um suporte narrativo. Dos desenhos rupestres até as pinturas do século XIX, a história da arte considera a imagem como um suporte narrativo, que graças às suas expressões figurativas se abre como um universo potencial de contos e relatos. Essa capacidade narrativa foi, sem dúvida, uma característica distintiva da pintura entre os séculos XIV e XIX, quando surge e se estabelece o gênero da pintura histórica, feitas para retratar grandes acontecimentos políticos (crises, guerras, coroações, revoltas), cenas bíblicas, mitológicas ou eventos dramáticos considerados de significado moral e de importância histórica.

As funções narrativas da pintura são colocadas em questão no início do século XX com as primeiras pinturas abstratas, cujo silêncio geométrico ou sinfonias cromáticas se revoltam contra as tradições acadêmicas e a arte oficial. Nas décadas seguintes, a arte cinética e a op arte estendem as pesquisas por novos recursos visuais, provenientes da ilusão de ótica e da percepção e de outros fenômenos como o movimento e a luz, enquanto o minimalismo, fortemente influenciado pelo construtivismo, demarca um território de produção dedicado à decomposição e à recomposição formal e a limpeza da forma. Todas essas tendências artísticas nas suas investigações da tridimensionalidade, - da abertura e da hibridação entre pintura e escultura, dos efeitos óticos e visuais, do contraste e da vibração das cores, das relações entre formas geométricas e linhas -, se afastam significativamente da narrativa e da construção de relatos.

Curiosamente, as primeiras décadas do século XXI surgem formas artísticas marcadas pela iconografia, pela cultura de massa, e pela narrativa fílmica; a associação de textos e imagens a serviço de uma narrativa e a vídeo arte se revelam como ferramentas próprias para contar histórias. Consequentemente, os questionamentos em torno das narrativas artísticas ressurgem, desta vez, solicitados sob as perspectivas das teorias narrativas, da ficção ou do testemunho documental.

Essas considerações iniciais servem como inspiração à edição presente, cujo desafio é mapear produções artísticas que exploram a narrativa, analisando seus suportes e dimensões intermidiáticas, e de uma maneira mais ampla, refletir sobre a narrativa no campo das artes visuais. Os artigos nesse volume, oriundos de pesquisas teóricas, de reflexões de artistas e de experiências estéticas refletem a aproximação entre artes visuais e outras áreas de conhecimento, tais como o cinema, a literatura, as teorias da linguagem, a narratologia e as ciências naturais.

Uma reflexão que analisa a linguagem cinematográfica de David Lynch sob o ângulo da estética disruptiva é feita por Karine Rouquet. A autora propõe uma leitura fina e atenta do filme "What did Jack do?" (2017), no qual Lynch nos convida a uma experiência sensorial onde a lógica narrativa se desintegra em uma inquiétante familiarité. Este curta metragem, para além da alegada herança do surrealismo, utiliza processos híbridos cômicos e fantásticos, que a autora examina retomando a inversão carnavalesca de Michaël Bakhtine, e, fazendo referência a "Elogio da Loucura" de Erasmo e às práticas das festividades medievais. 
Karine Rouquet nos apresenta Lynch como um Mestre do Absurdo, que se diverte colapsando os códigos narrativos e visuais do filme noir, ou seja, de sua própria filmografia, criando uma estética turbulenta capaz de desafiar a plataforma disruptiva sobre a qual se faz sua estreia. Na interpretação dos elementos visuais, textuais e cinematográficos, Rouquet mobiliza um repertório enciclopédico e original, que ressalta as dimensões literárias e teatrais do filme de Lynch, ao mesmo tempo que propulsa trajetórias inéditas de apreciação.

A estética da imagem cinematográfica é abordada também por Eithne O’Neill, por meio da construção de um paralelo entre a obra cinematográfica dos irmãos Stephen e Timothy Quay e "O Grande Vidro" (1915-1923) de Marcel Duchamp. Em sua análise, a autora estabelece um conjunto de conexões que partem das influências literárias dos irmãos cineastas, como Raymond Roussel, Robert Walser, Bruno Schulz e Franz Kafka. Aponta em comum certos procedimentos técnicos de montagem, assim como o uso de materiais mecânicos e orgânicos como componentes das obras. "O Grande Vidro", assim como a obra dos irmãos Quay, constroem narrativas que incorporam um mundo de sonhos e desejos. A noiva e os celibatários aprisionados entre as lâminas de vidro trincadas de Duchamp, segundo a relação criada pela autora, parecem desempenhar papéis em “Institute Benjamenta” (1995) dos Quay. O artefato “definitivamente inacabado” que constitui "O Grande Vidro" é uma montagem de componentes diversos, com múltiplos materiais, formas simbólicas e figurativas, que encontram eco nas animações e filmes dos Irmãos Quay.

Alguns artigos se utilizam de textos, artefatos culturais e históricos que servem como catalisadores de histórias, como se elas tivessem ocorrido, que em conjunto com imagens ou objetos produzidos pelos artistas, modelam novas relações e conexões em contextos que the são próprios. É com esse objetivo que Daiana Schropel, artista e pesquisadora, desenvolve um corpo de ações baseados em montagens com fragmentos disparadores de uma ficção, mantendo necessárias referências para tornar quase crível o forjado "Instituto Allotria” (2020) e a biografia da personagem “Elena Landkraut" (2020). Se poderia dizer de uma qualidade aditiva (HILL, 2001) desses enredos visuais e ficcionais, que implicam em tal soma ou acúmulo de procedimentos artísticos que dão corpo às superficções, resultando em instalações físicas, objetos e textos que pretendem sustentar uma verossimilhança com eventos históricos e seus documentos, tanto incorporando componentes inventados, quanto reais.

Ao comentarem três obras de Walmor Correa, os autores Matheus Furtado e Sara Scholze reputam de pequenos enganos o resultado obtido com as operações artísticas do artista que, também como Schropel, tentam convencer da existência real das coisas fabuladas, mesmo que, por parte do público, haja consciência da finalidade artística dos trabalhos.

O tratamento primoroso aplicado aos desenhos e objetos, que emulam os seres quiméricos de "Biblioteca dos enganos" (2009), “Memento Mori” (2007) e “Natureza Perversa” (2003), e a exibição em armários envidraçados de boticário, evocam os arranjos dos museus de história natural e a tradição dos gabinetes de curiosidades do século XVI, compondo os fatores responsáveis pela persuasão e engajamento do público.

A estrutura de apresentação dos trabalhos com montagens e fragmentos tem formas diferentes dentre as contribuições recebidas para o dossiê. Se a multiplicidade de ações, de 
personagens e de fatos fabulados constroem superficções, - partes que idealizam um mundo para "Elena Landkraut", para o "Instituto Allotria" e para as curiosidades de Walmor Correa, e proporcionam alguma interpretação linear, embora ambígua, a esses trabalhos, - outros exemplos formam, ao contrário, congregações poéticas pouco atentas aos significados lógicos. Como exemplos, a obra de Letícia Bertagna, comentada por Ana Paula El Jaick, e as estampas do artista e pesquisador mexicano Juan Iván Gonzales de León.

A produção de Gonzalez de León, representada na capa desta edição com o trabalho "Hombre-ave" (2021), é emblemática de uma reunião e justaposição de referências. Suas estampas engendram textos visuais que simetrizam o reconhecimento do indivíduo contemporâneo com lastros na cultura popular, na iconologia mesoamericana, e na representação de signos e caracteres racionais rigorosos e metódicos do pensamento humano.

Desafiando o estado das coisas comuns, El Jaick explica que Bertagna promove paradoxos visuais ou verbo-visuais que geram o descolamento e até mesmo o choque dos sentidos convencionais daquilo que se vê ou lê. O foco da produção da artista é a fotografia, com a qual mantém duas linhas de ação: Em uma delas, nas fotografias de cenas cotidianas performadas pela artista ou por convidados, os corpos posicionam-se em estranhas conjunções com o ambiente, como se pudessem ser figuras híbridas, - uma casa que é corpo e um corpo que é casa; em outra composição, os jogos verbo-visuais tornam-se a tônica do trabalho, que tem a contradição como recurso de enunciações. Esse é o caso da obra "Fundo do fora (Lembrete)" (2015-2020), onde se vê a imagem de uma pequena folha de nota, um post-it, com a palavra esquecer.

Brigida Medeiros traz um paralelo entre o conceito de autoficção proposto por Serge Doubrovsky e as produções autobiográficas e ficcionais de Rosangela Rennó e Cindy Sherman, oferecendo mais exemplos da constelação de sentidos promovida pelas contradições, aproveitando o termo aplicado por El Jaick. Em “Espelho Diário” (2001) de Rosângela Rennó e Alícia Duarte Penna, a narrativa ancorada no texto e na imagem formam uma espécie de diário, elaborado com base na seleção de notícias que envolveram pessoas com o mesmo nome da artista. Em "Untitled Film Stills" (1977-1980) Cindy Sherman se auto retrata representando e parodiando personagens femininas do cinema, também como uma mimese da cultura. Assim, em ambas produções, mantem-se algum cunho documental, - elementos reconhecíveis, personagens e fatos que produzem um estado de alerta no espectador -, e o desejo de veracidade da autobiografia une-se à ficção de maneira paradoxal pois, as duas formas, “[...] em princípio, deveriam se excluir.” (FIGUEIREDO, 2010, p. 91)

A imagem estática com aptidão narrativa, e dessa vez fabulosa, é realçada no álbum familiar de Ralph Eugene Meatyard, analisado por America Cupello, que transforma familiares e amigos próximos em personagens mascarados de situações cotidianas, - uma viagem, um passeio pelo parque, uma pose à porta de entrada da casa. Também nessa obra, a perspectiva paradoxal pode ser associada à descaracterização parcial dos familiares, pois, em primeiro lugar, faz estranhar a própria intimidade tornando pessoas muito próximas desconhecidas; em segundo lugar, embora o mascaramento seja indicativo de uma abordagem lúdica dada às questões existenciais da passagem do tempo e da constatação do envelhecimento, escancaram a finitude da vida justamente ao escondê-la com os aparatos da cena. 
Em um ensaio teórico-visual Patrícia Andrea Soto Osses explora o entendimento de feminino apoiado em um conjunto de ações performáticas de sua autoria, que estabelecem um jogo temporal com a literatura de Marguerite Duras. A partir de sua vivência em cidades francesas, Trouville e Nevers, conectadas com a diretora e sua obra "Hiroshima meu amor" (1959), a narrativa construída dialoga com o acaso e o inesperado. Ao percorrer alguns dos lugares literários, as relações espaciais envolvidas nesse processo, e a presença corporal dotada de uma intenção artística, despertaram na autora reflexões na percepção do feminino como falta e silêncio. As camadas temporais construídas por Osses são criadas a partir de conexões entre literatura, cinema e artes visuais, e promovem uma sobreposição entre realidade e ficção.

Em todos esses trabalhos, com maior ou menor grau de referencialidade, os elementos da realidade atuam para corroborar com o enredo e com o contexto da existência das personagens. Entretanto, as ruínas registradas por Lucas Gervilha, assim como qualquer outro elemento da arquitetura em condições precárias, tem o potencial de alçar o lugar, compreendido em sua materialidade, como protagonista do mundo narrativo criado pelo vedor. Esses lugares declinam do valor de uso original ao se darem a ver enquanto fenômenos das alterações do tempo: nas ruínas o mistério implica tanto o passado quanto o futuro, motivando conjecturas e devaneios que se realizam na imaginação.

O artigo do narratologista suíço Raphaël Baroni apresenta um panorama de relações entre imagem e narrativa. Procura distinguir três maneiras, não excludentes mas sim complementares, de conceituar a narratividade e suas relações: a primeira é definida por uma representação sequencial de eventos, que articula uma dimensão temporal; a segunda coloca o receptor em questão, na medida em que se refere a narrativas que pressupõem o reconhecimento de eventos narrados, que se desenrolam em uma trama; a terceira é desenvolvida por Paul Ricoeur (1983), que entende que os eventos narrados devem formar uma totalidade. Dentro desse espectro conceitual, o autor aponta que o potencial narrativo da imagem pode se articular pela apresentação de uma sequência seriada sugerindo um fluxo temporal; por uma única imagem estática, representando um instante crítico, sugerindo uma continuidade, um resultado previsível; ao veicular algum tipo de enigma que requer uma interpretação que leva à síntese de uma compreensão. Os diferentes procedimentos de organizar o tempo e uma narrativa com imagens estáticas, solicitam a participação do espectador.

Na entrevista concedida por Lorenzo Menoud a Nikoleta Kerinska, o artista e escritor tece uma série de considerações teóricas sobre os conceitos de narrativa e narratividade, seus objetivos, alcance e uso. A partir de um alargamento no âmbito da narratologia estruturalista, sustentado por autores como Claude Bremond (1966) e Roland Barthes (1964), Menoud reflete sobre a narratividade das obras de arte visuais, assim como de outras formas artísticas ou não-artísticas de narrativas, reais ou ficcionais; procurando compreender a narratividade mais como uma questão de escala do que como uma separação binária das representações mentais. Propõe analisar as narrações como uma relação entre quem as produz e quem as recebe, renunciando à distinção clássica entre showing e telling em relação às diferentes práticas artísticas. Menoud entende que a narratividade e a ficcionalidade, por sua vez, não interferem na determinação do estatuto artístico da obra, e que os campos artístico, ficcional, literário e narrativo, fazem parte do campo das representações. 
O ensaio de Stéphanie Katz relata a experiência poética vivida pela autora durante a retrospectiva da obra de Ph. Parreno apresentada em 2013 no Palais de Tokyo. Katz demonstra por meio de uma descrição sutil, como o artista inverte a dupla herança das máquinas individuais de Duchamp, por um lado, e dos ícones de Warhol, por outro, para o campo das tecnologias visuais da Sociedade do Espetáculo. A figura de Marilyn, apreendida como um motivo trans-histórico flutuando entre anunciação, estrela e fantasma, realça a constância do projeto da imagem ao longo dos desenvolvimentos históricos e técnicos para designar a não representabilidade da morte. Esses elementos são examinados pela autora em um questionamento subjetivo do seu estatuto de espectadora e de consumidora de arte. Evocando noções como identidade e memória, o ensaio de Stéphanie Katz se desenvolve como uma narrativa sobre a narrativa, paradoxalmente marcada pela sucessão e pela atemporalidade.

A problemática dos relatos históricos é central no artigo de Nathanaël Wadbled intitulado "Que faire des témoignages plastiques à Auschwitz-Birkenau: Effacement et présence de ce que racontent des œuvres visuelles”. O autor faz uma reflexão sobre os museus memoriais da deportação nazista e do genocídio, e questiona a rara exibição de desenhos, pinturas e esculturas produzidas por sobreviventes que representam sua experiência de horror. No caso particular da exposição no Museu Memorial de Auschwitz-Birkenau, a maioria das imagens exibidas são fotografias. Quando são apresentadas obras testemunhais, as faz em um espaço distinto e separado da exposição histórica. Segundo a hipótese de Nathanaël Wadbled, o discurso sobre o Holocausto veiculado pela exposição dificilmente o deixará um lugar para essas obras. A disparidade se dá pelo fato de que a exposição histórica mostra a incomensurabilidade do horror, enquanto esses testemunhos plásticos induzem a imaginar a história da vida das vítimas, revelando uma dimensão humana. Desse modo, as obras representativas confrontam o espectador com a evidência da experiência do horror, e não com sua inefabilidade.

Para finalizar, esperamos que esse número seja uma contribuição e uma leitura prazerosa para os admiradores das narrativas, para os artistas e os teóricos das artes que se encantam pelo ato de contar e pela linguagem. Certamente, a temática do uso da linguagem em relação ao fazer artístico e do esforço poético de apreender a realidade humana por meio do texto e da imagem forma um rizoma de caminhos e de alternativas, cujas derivas escapam a qualquer tentativa de tentativa de dimensionamento. Concluiremos, portanto, assim: ...era uma vez uma espécie que tentava compreender a sua razão de ser, e fazendo isso contava suas histórias. 


\section{Referências}

ANDRE, Sylvie, Le récit. Perspectives anthropologique et littéraire, Paris, Honoré Champion, coll. Unichamp Essentiel, 2012.

BARTHES, Roland. Introduction à l'analyse structurale des récits, Communications, 8, 1966. Disponível em https://doi.org/10.3406/comm.1966.1113 Acessado em 30/05/2021.

BREMOND, Claude. Le message narratif, Communications, 4, 1964. Disponível em https://doi. org/10.3406/comm.1964.1025 Acessado em 30/05/2021.

FIGUEIREDO, Eurídice. Autoficção feminina: a mulher nua diante do espelho, Revista Criação \& Crítica, n. 4, p. 91-102, 2010. Disponível em http://www.fflch.usp.br/dlm/criacaoecritica/ dmdocuments/08CC_N4_EFigueiredo.pdf. Acessado em 30/05/2021.

HILL, Peter. Superfictions. The Creation of Fictional Situations in International Contemporary Art Practice, 2001. 161 p. Exegesis (Ph.D.). Melbourne: RMIT University, 2001.

RICOEUR, Paul. Temps et récit. Paris : Seuil, 1983.

VICTORRI, B. "Homo narrans : le rôle de la narration dans l'émergence du langage". Langages, numéro thématique : L'origine du langage. Année 2002 / 146 pp. 112-125. Disponível em https:// www.persee.fr/doc/lgge_0458-726x_2002_num_36_146_2406. Acessado em 30/05/2021 


\section{Sobre os autores}

Fabio Fonseca é docente do curso de Artes Visuais da Universidade Federal de Uberlândia (UFU), na subárea de Desenho. Doutor em Teoria e Históriada Arte pela Universidade de Brasília (UnB), com período sanduíche no Centro de Linguística da Universidade de Lisboa. Mestre em Teoria e História da Arte pela UnB. Especialista em História da Arte do Século XX e Bacharel em Gravura pela Escola de Música e Belas Artes do Paraná (EMBAP-PR). Atualmente desenvolve sua pesquisa sobre o processo de sobrevivência das imagens, procurando integrar sob um viés teórico-metodológico, a pesquisa em Teoria e História da Arte com a produção prática em Artes.

LATTES: http://lattes.cnpq.br/4450453554832020

ORCID: https://orcid.org/0000-0002-1371-5502

Nikoleta Kerinska é uma artista multimédia, pesquisadora e professora de arte computacional. O foco de sua pesquisa é o uso da inteligência artificial em projectos de arte e a realidade virtual. A sua actividade artística é inspirada pelas convergências e divergências na comunicação homemmáquina, bem como pelas trocas poéticas entre linguagem natural e imagem. Actualmente é professora associada no Instituto de Artes, Departamento de Artes Visuais da Universidade Federal de Uberlândia (Brasil).

LATTES: http://lattes.cnpq.br/9119298795241795

ORCID: https://orcid.org/00oo-0001-5486-1381

WEBSITE: https://nk.artificialis.org/

Priscila Rampin é artista visual e pesquisadora. Em 2021 publicou o fotolivro Fatos Instáveis. É doutoranda em artes pela Universidade de Brasília (UnB), mestra pelo Programa de PósGraduação em Estudos Contemporâneos das Artes da Universidade Federal Fluminense e bacharel em Artes Visuais pela Universidade Federal de Uberlândia. Foi docente das disciplinas de gravura e arte têxtil na Universidade Federal do Oeste da Bahia (UFOB). É editora do periódico científico Estado da Arte - Revista de Artes Visuais IARTE/UFU.

ORCID: https://orcid.org/oooo-0002-8464-7586

\section{Como citar}

FONSECA, Fábio; KERINSKA, Nikoleta; RAMPIN, Priscila. (2021). Narrativas artísticas: ramificações, contaminações e apagamentos. Revista Estado da Arte, Uberlândia. v.2, n.1, p.15-23, jan./jun. 2021. https://doi.10.14393/EdA-v2-n1-2021-62551 